\title{
Becoming Professional: Exploring Identity Construction of Non-native CFL Teachers
}

\section{Chun Zhang and Danping Wang}

\section{INTRODUCTION}

The demand for qualified teachers of Chinese who are able to work professionally and interculturally in specific educational and cultural contexts has become high (Moloney 2013; Wang and Kirkepatrick 2012). However, some researchers argue that many native Chinese as a foreign language (CFL) teachers trained in China's CFL teacher education programmes often lack intercultural background and linguistic knowledge to manage classroom learning effectively, consequently discouraging students (Orton 2011; Starr 2009). As a result, universities outside of China have begun resorting to recruit non-native CFL teachers from local supply in order to meet the demands of CFL courses. In the case of Denmark, many recently employed non-native CFL teachers are young graduates from universities holding a degree in Chinese studies. Understanding how non-native CFL teachers construct their professional

C. Zhang $(\bowtie)$

Department of Culture and Society, Aarhus University, Aarhus C, Denmark e-mail: ostzc@cas.au.dk

D. Wang

School of Cultures, Languages and Linguistics, University of Auckland, Auckland, New Zealand

e-mail: danping.wang@auckland.ac.nz

(C) The Author(s) 2017

T. Jin, F. Dervin (eds.), Interculturality in Chinese Language

Education, Palgrave Studies on Chinese Education in a Global

Perspective, DOI 10.1057/978-1-137-58322-2_5 
identities as Chinese teachers is an urgent issue in that the demand for qualified non-native CFL teachers is increasing (Zhang and Jensen 2013), and their supply is rather limited (Wang et al. 2013). Therefore, it is crucial to understand the new, non-native, CFL teacher's path of becoming a teacher, particularly during the initial year of their teaching career. Situated in a Danish educational and cultural setting, this case study seeks to answer the following research question: How do non-native CFL teachers construct their professional identities in Danish higher education?

This chapter is original in three ways. First, this study calls for the voices of non-native CFL teachers to be heard through research endeavours. Second, the study offers some insights for young, non-native CFL teachers, who struggle to develop professional identity, to become qualified Chinese teachers. Third, this chapter calls for recognising the special merits of non-native CFL teachers through empirical data.

The chapter begins with a literature review on foreign language teacher identity, with a focus on Wenger's (1998) identity theory as the conceptual framework. Then, it outlines important background knowledge of non-native CFL teachers in the context of Danish higher education. Next, the chapter introduces information on research setting, participants, and methods of data collection and analysis. The main body of the chapter is organised under two thematic headings. The paper discusses and concludes with a discussion of findings. Finally, the chapter identifies some limitations and provides some suggestions for future research.

\section{Literature REVIEW}

Research on the professional development of language teachers has recently attached great importance to professional identity. Some researchers claim that 'developing an identity as a teacher is an important part of securing teachers' commitment to their work' (Hammerness et al. 2005 , p. 383 ). New teachers undergo a transition in personal and professional identity, as they change from the role of student to that of teacher (Gu and Day 2013). Varghese et al. (2005) state that identities are not stable or fixed, but dynamic, multifaceted, and conflicted' (p. 22). The dynamic and multiple qualities of teacher identity construction are explained in Britzman's (2003) view of learning to teach as 'a process of becoming'. In view of research on identity among foreign language teachers, Clarke (2008) points out that novice teachers are constantly involved in the construction and reconstruction of their identities. As 
the concept of 'becoming a teacher' highlights the dynamic nature of identity (re)construction, it is reported that some new teachers' thinking may also be largely influenced by what they have experienced as language learners (Tsui 2007). In addition, Trend's (2013) study pays attention to understand new teachers by looking at their 'language learning trajectory', claiming that 'identity as a trajectory' focuses on the multiple boundaries that each teacher crosses as they are in a journey of being a teacher to becoming a teacher. This attention is important when conducting CFL teacher identity research from intercultural perspectives in that foreign language teachers' learning trajectory is associated with the interaction of different cultural values. Wang and Jensen's (2013) study further reveals that local CFL teachers' beliefs are the 'products of the collision between Chinese and Danish educational cultures' (p. 109). Yet, while insightful, there has been much less studies focusing on how new local non-native CFL teachers understand themselves and develop their professions in their home country. This is an area deserving research attention, which has been unfortunately under-researched from a teacher identity point of view.

In order to gain a better understanding of non-native teachers' identity construction, we used Wenger's (1998) framework of social identity theory as the theoretical framework. Wenger (1998) proposes, 'one's identity lies not only in the way one talks or thinks about oneself, or only in the way others talk or think about one, but in the way one's identity is lived day-to-day' (p. 99). Wenger (1998) explores identity construction as an experience, in terms of three modes of belonging: engagement, imagination, and alignment. Engagement allows us to invest in what we do, and in our relations with others, gaining 'a lived sense of who we are' (p. 192). Imagination refers to 'the creation of images of the world, and our place within it across time and space, by extrapolating beyond our own experience' (ibid. p. 177). Alignment coordinates 'an individual's activities within broader structures and enterprises, allowing the identity of a larger group to become part of the identity of its members' (ibid. p. 179).

\section{Research Design}

Narrative inquiry was used for exploring the identity construction of nonnative CFL teachers. Connelly and Clandinin (1990) refer to teachers' professional identities in terms of 'stories to live by' (p. 4). According to them, stories provide a narrative thread that teachers draw on, to make 
sense of their experience and of themselves. Although some critics raised doubts about the validity of narrative inquiry using verbatim quotations from the participants (Beijaard et al. 2004), it should be noted that 'life stories' do not only tell the researchers about their participants' personal experiences but also most importantly 'they can help researchers to understand the experiences of participants and cultures, and contribute to the structuring of identity' (Gibbs 2007, p. 60). Therefore, the narrative approach was justifiably adopted to carry out this study on teachers' professional identities.

\section{Setting}

The study was undertaken at the Department of Chinese Studies at University A in Denmark. The first degree in Chinese Studies was established in the late 1960s, now it offers Bachelor, Master, and $\mathrm{PhD}$ programmes. During the 2012 and 2014 academic years, there were 92 students in these programmes, and four language teachers - two native and two non-native CFL teachers.

\section{Participants}

The study followed a purposive sampling method in recruiting participants. In this study, we need participants who (1) had experience of teaching and learning in Chinese and Danish cultures; (2) were teaching Chinese in Danish context at the time of the data collection; and (3) were willing to share personal and professional experience with the researchers. As non-Chinese CFL teachers remained a very small group of community, only a handful of Chinese teachers from them were suitable for this study. Due to the limited space of this chapter, we focused on the two participants' identity construction process with in-depth analysis of the narrative data. Agnes obtained her MA degrees in Chinese Studies in 2011, and Frank obtained his MA degree in 2014. The two participants were very reflective of their experiences of learning and teaching Chinese. They both had been to China to study Chinese before they took the current teaching position. To protect their privacy, we have assigned each participant a pseudonym. Participants' names and personal information have been changed or otherwise anonymised to protect their privacy.

Agnes was in her early 30s when the research was conducted. She was born and educated in Denmark. Agnes holds a BA and a MA in Chinese studies 
from University A, and is currently doing a $\mathrm{PhD}$ degree. Apart from learning Chinese at University A, she studied Chinese at various Chinese universities as formal part of her studies for two years while pursuing her degrees.

Frank was born in the mid-1980s to an American-Danish family in Denmark. Growing up in a bilingual family, Frank developed a strong interest in foreign languages and cultures in his early childhood. He completed his BA and MA in Chinese Studies at University A. While pursuing his degrees, Frank went to study Chinese in a Chinese university for six months.

\section{Data Collection}

We started with an individual questionnaire to gain basic personal information, including the subjects they taught, experiences of learning and teaching CFL, and reflection on the experiences. The questionnaire was in English. One participant responded in English, the other in Danish. A series of semi-structured interviews were then conducted. We interviewed Agnes three times, but due to time limit, we interviewed Frank twice. Each interview lasted about 30 minutes. The interviews took place at the office of the first-author, and were audio-recorded and transcribed for data analysis. We posed open questions to Agnes and Frank about the decision to study Chinese, experiences as CFL learners in Denmark and in China, and reflections on their learning and teaching relating to identity of CFL teachers. Interviews were done mainly in English, and occasionally a mixture of both Danish and Chinese was used to express certain notions, such as Danish idioms and fixed Chinese phrases.

\section{Data Analysis}

The data were analysed according to Wenger's (1998) framework, to demonstrate their professional identities as non-native CFL teachers. Descriptive and narrative data were first sorted chronologically, beginning with Agnes's and Frank's decision to study Chinese as their major, to their first year of teaching Chinese to Danish students. Following this, the data were sorted according to the identity formation and different life experiences in the Danish University A as well as in Chinese universities. This process also involved 'reorganizing their recollections' (Strauss and Corbin 1990) because it was important to understand the unrest and uneasiness they experienced when they were the learners of Chinese in two different countries. 


\section{FINDINGS}

This study presents the three key aspects of the research findings: establishing CFL learner identities, exploring CFL teacher identities, and becoming CFL teachers. To understand the journey that Agnes and Frank took to become Chinese language teachers, we start by looking at their motivations for choosing to learn Chinese.

\section{Establishing CFL Learner Identities}

\section{Setting Out on an Unknown Journey}

At the beginning of their interviews, Agnes and Frank explained their reasons for studying Chinese, and their families' and friends' attitudes towards that choice. From a young age, Agnes was fascinated by Chinese culture, reading magazines about China. It was not until her high school classmate introduced her to a programme of Chinese studies that she decided to study Chinese at the university.

My parents and my friends thought it was weird. My father was unhappy about my choice. He was very sceptical about it, and worried that I could not find a job after graduation. But my mother supported my choice, and advised me to study hard, if this was what I really wanted to do. (Agnes)

Clearly, in the eyes of Agnes's parents, about 10 years ago, choosing to read Chinese might not be a good way to secure a well-paid job. Therefore, her parents were a bit 'unhappy' and 'sceptical'. However, Agnes found herself 'fascinated' by Chinese culture, and her mother was supportive of Agnes's decision regarding her studies. Agnes also indicated her low level of interest in learning the Chinese language. Unlike Agnes, Frank's parents' attitudes were liberal, and they were 'delighted' when Frank decided to learn an 'exotic' language simply because he was interested in foreign cultures and languages. Frank stated:

My parents were delighted with my decision to learn an 'exotic' language.... But in general, my parents warmly supported my choice. They thought China would become a big economy in the future. And they were right! [Laughter]

For the two participants, their early motivation to study Chinese language was largely integrative (Dörnyei and Ushioda 2009), which 
might be a key impetus for successful language learning. However, the two participants did not have a definite idea of becoming Chinese language teachers. With little prior knowledge of what Chinese learning and teaching could be, their courage to set the foot on an unknown journey deserves respect and research attention. Yet, it is also expected that the construction of their professional identities as non-native Chinese teachers would carry a sense of uncertainty and uneasiness. Their parents' attitudes towards their decision to learn Chinese were a little more instrumental and practical, as choosing what to study was regarded as closely associated with future jobs.

\section{Learning About the Language Not Learning to Use the Language}

In our study of understanding how Agnes and Frank relate others' response to construct their own identity, we take account of their experience of establishing CFL learner identities. One important aspect is to look at how they compare different teaching methods they encountered while they were CFL learners in Denmark and in China. Agnes recalled some of her experiences as a CFL learner in Denmark.

Chinese teachers here are very strict with tests and classroom attendance. The atmosphere was formal and teachers look serious. (Agnes)

One important experience while studying abroad further shaped Agnes' CFL learner identities. Agnes went to Beijing to learn Chinese in her second year. Her arrival at university B in Beijing in the early 2000s added another identity as a learner of the Chinese language in China. 'liú xuéshēng' (留学生), foreign/international students, with a very clearly defined role in Chinese culture, marked the beginning of her first experience of language immersion as a CFL learner in a Chinese-speaking context. She stayed at a small teacher's college in the outskirts of Beijing. In contrast to the majority of foreign students, who were taking the elementary language classes together, Agnes went to an advanced language class right from the beginning. During these classes, Agnes had to cope not only with the different accents of her teachers but also with various teaching methods. In the beginning, Agnes found almost impossible to follow the class. Agnes said:

The teaching method used by the Chinese teachers there was VERY different from that of my Chinese teacher in Denmark... Some of the teachers 
there [China] were just repeating.... We would just write down where the word would be in the sentence, but we did not use them. It was the same method over and over again...We've learned a lot of vocabulary, but we never had any chance to actually use it outside of class. (Agnes)

Like Agnes, after a year and a half of learning Chinese in Denmark, Frank went to Zhejiang to study Chinese. His arrival in Hángzhōu (University C) as a 'liú xuéshēng' gave him a new experience in a Chinese-speaking context. Already in his mid-20s, Frank had to learn to build new networks of friends and to live in a new country, operating in a foreign language, though perhaps more in the anticipation than the reality. Being born into a bilingual/bicultural family, Frank had learned to live quite confidently in Germany and America. But learning to cope with China seemed much more daunting. The following excerpts illustrate Frank's early experience of Chinese learning and his observation of what motivated international students, and what did not.

It is a different way of teaching Chinese in China.... I remembered the first time we had a 'jī ngdú' (精读, intensive reading) teacher... she was always smiling. She encouraged the students to talk a lot. In her class, everyone was talkative, feeling nice and loose.... Then I had 'kǒuyǔ' (口语, conversation) class with a different type of teacher, a little bit stricter. She corrected every mistake we made. People seemed less willing to participate. (Frank)

As stated above, for non-native language teachers, it is of crucial importance to examine their learning experience, as their professional beliefs may be profoundly influenced by the teachers who taught them to speak the language. Recalling the good and bad memories helps to reconstruct their learner identity, this in turn provides direct references for them to construct their professional identities as teachers. During the interviews, the two participants consciously juxtaposed the learning experience they had as language learners with the teaching experience they hope to give their students. Frank concluded his learning experience by saying that:

I want to be a teacher or the kind of teacher good at engaging students in class. So I noticed it, as I felt comfortable in the class, and so did everyone. When we are relaxed and are not afraid of making mistakes, we become eager to attend the class and work harder. It's an interesting experience. You can see how different the teachers are and how we are willing to learn. (Frank) 


\section{Constructing CFL Teacher Identities}

Avoiding Practicing 'Chinese' Way in a Danish Context

Aside from establishing learner identities, the study findings also point to a fact that the past CFL learning experience played a significant role in influencing their current views in becoming teachers. As non-native CFL teachers, Agnes and Frank are fully aware of the applicability of the 'Chinese way' of teaching languages. Their intercultural understanding of Danish teaching culture and Chinese teaching culture tells them that this 'strict' teaching approach would not be acceptable in a Danish context and therefore it would not be applicable in the local classroom. Agnes started to teach Chinese to first- and second-year students in the 2011/ 2012 academic year. After she came back from China, Agnes began to teach a Chinese class to first-year students at a Danish university. She recalled:

I introduced newspaper-reading class to my students. In this class, students are free to choose the texts by themselves. I had a similar class while I was in Beijing. I liked my teacher for the newspaper-reading class [in China]. In her class, we actually used a lot of new words learned from the text. (Agnes)

The way I teach is inspired by what I've been through. This works and this does not work, and combine... I never had any experience as a teacher before, but an experience as a student. (Agnes)

Frank started to teach Chinese grammar to second-year students in the $2013 / 2014$ academic year. His teaching method has also been largely influenced by what he had experienced, keeping the methods that he thinks useful, and discarding the ones that he found ineffective. The following excerpt should make it clear.

I don't want to be too strict like my 'kǒuyǔ' teacher there.... To give the students a positive experience, maybe not so afraid of making mistakes ... It is hard to say my teaching method is a Danish way, I think it is sort of combination, something in between. (Frank)

In recounting the experiences that gave rise to their professional identities as teachers, both Agnes and Frank placed emphasis on comparing the teaching they had experienced in China and the methods they adopted when they taught Chinese. Looking at these issues from a broader point of 
view, it is not hard to see that they were trying to relate their personal learning experience to their professional identities. In Frank's case, the question is about building a friendly learning atmosphere. He believes in the importance of being a friendly teacher in order to learn the language; so his pedagogical approach is to 'give a positive experience to the students'. Yet, how might their personal identities as learners and teachers affect or contribute to the shaping of their professional identities? The third key findings may illustrate this point.

\section{Having Good Relationship with Students and Building Up Safe Learning Environment}

As outlined in Wenger's (1998) framework, identity construction is related to alignment. It can be understood as a sense of positioning in relation to what standpoint they hold. Therefore, in this study, we take account of how Agnes and Frank position themselves in relation to their students. The following excerpts illustrate how they manage their sense of positioning. Agnes put it:

Well, I think it is still a teacher and student relationship... but there is another aspect. We are more or the less same age. So, some of the students are only a couple of years younger than me... But I hope they don't see me as a fellow student. (Agnes)

For Agnes, becoming a CFL teacher is a further step on a journey of constructing professional identities in which she is able to prove her choice and hear herself being recognised by the students. Her intercultural experience as a learner in China plays an important role in constructing her professional identities. She gained new teaching methods and developed new pedagogical approach. For Agnes, becoming a CFL teacher is to gain recognition from the students not due to the teacher position, but due to teachers' ability to communicating with the students. This sense of communication is further reinforced by Frank's excerpt.

It is also an obstacle, trying it out and seeing how I am as a 'lăoshī' (老师 teacher). Am I a teacher yet? So far, I feel like something between. I feel like a student, but [also] like their teacher. I am not good at spoken Chinese as my native Chinese colleagues. But I hope that they feel they are sort of equal to me, so that they'd ask me questions... I've been in their shoes... But at the same time, I hope they regard me a little bit as their teacher. (Frank) 
As Frank explains, such a dilemma of language-related profession in the case of CFL teacher can be imposing a burden on him, who see a need in their personal and professional path for acceptance and recognition. From this point of view, someone born 'Agnes' or 'Frank', who would normally be classified as 'Danish' (however tenuous this may be, in Frank's case), should surely feel uncertain about teaching Chinese, unless they have a good command of the language they teach, and gained an acknowledgement from the local. Living many years with the identities of CFL learners, in their personal contexts, the learner identities 'liú xuéshēng' had become almost exclusive labels when they were operating in Chinese settings, both in China and in their Chinese-learning settings outside of China. In their professional contexts, their learner identities seemed to get less salient. They hope, though have not explicitly said, that their students regard them as teachers, and that they would recognise the special merits that non-native CFL teachers possessed in that they had been 'in students' shoes' quoted by Frank.

\section{Discussion AND Conclusion}

\section{A Lived Experience of Identity Construction}

For Wenger (1998), identity is 'an experience and display of competence' (p. 152). Engagement in practice is crucial to identity construction, because 'our definition of competence shape our identities through our very engagement in activities and social interactions' (p. 193). When Agnes chose to study Chinese, although she did not receive support from her parents, she studied hard to prove that her choice was right. At University A, both Agnes and Frank not only experienced a new learning environment but also encountered a different teaching method. The new learner identity seems to have had an effect on their sense of self and identity. Studying CFL in China was an eye-opening experience for them. Owing to the different context and different teaching approach, Agnes and Frank felt learning Chinese in China was different from what they encountered before. Agnes emphasised that the teaching method in China was very different from what she was used to. Frank recounted that his teachers in China were 'too strict'. The identity conflicts were triggered by their later observation of Chinese teaching pedagogy while they were in China. The changing views of Chinese teaching philosophy caused a conflict in their identity construction as a Chinese teacher. For example, 
Agnes and Frank believed that developing a high level of Chinese proficiency meant gaining communicative skills. They considered the intensive teaching of language structures, texts, and vocabulary by their Chinese teachers 'monotonous' and 'boring'.

Wenger's (1998) second mode of belonging is imagination. It refers to 'transcending our time and space and creating new images of the world and ourselves' (p. 176). For example, through teaching, Agnes and Frank created a broader sense of self. Frank captured the gist of this in his anticipation of not wanting to "be too strict like my "kǒuyŭ" teacher'. He wanted to become a teacher like his 'jingdu' teacher, who was engaging in her teaching, and encouraging. Agnes anticipated becoming a teacher like her 'newspaper teacher', who introduced plenty of extracurricular activities. The effort of anticipation and imagination was important in allowing the teachers to situate their engagement in the here and now of teaching, within the ongoing construction of their teacher identity. Thus, Agnes and Frank linked the images of themselves as 'jingdu' teacher and 'newspaper' teacher to the past. At the same time, imagination connected their identity construction in the here and now of teaching classes to the ongoing construction of their teacher identities. This presented a futureoriented picture of the 'world of teaching', and their place within it situated identity formation 'as a work in progress' (Wenger 1998, p. 158).

The third mode of identification is alignment. Alignment allows us to see the effectiveness of our actions beyond our own engagement. The ability to align with something entails knowing how to engage with others, and understanding the actions in which others are engaged. When they taught at University A, Agnes and Frank were formally reified as teachers through a teaching practicum, but they felt they were not fully accepted as teachers by their students. To be fully recognised as teachers, Agnes and Frank aligned themselves with the methods used by their favourite teachers. Among other things, this included being able to introduce extracurricular activities, creating a friendly learning environment; and, most important of all, being regarded as 'lăoshī'. This mode of address was particularly interesting in that it reflected the ability of alignment to help the new non-native CFL teachers situate themselves, and teach to what they experienced CFL teaching in China. 


\section{Identity Construction Intermingled with Intercultural Growth}

The lived experiences of having oneself accepted are important aspects of identification. For beginner teachers, the fresh memories and experiences as learners influence their ways of teaching, as well as their understanding of working as teachers. Firstly, guided by Wenger's (1998) framework, the research reveals that identification involves not just engagement, imagination, and alignment, but also, negotiation of meaning. Although they succeed in combining or finding an appropriate approach to teaching Chinese, they have to negotiate pedagogical and intercultural predicament. As native Danes, they are accustomed to the teaching and learning behaviour manifested in their home culture. The CFL learner identity, that is, 'liú xuéshēng' (foreign language student) collapses into the identity of Danish, which makes it difficult for them to understand the teaching behaviour of their teachers from a different culture. Yet, the position taken by Agnes and Frank seem to be problematic: On the one hand, they find it hard to adapt to the environment with serious discipline in learning CFL, and on the other, they increasingly appreciate the effectiveness of some of CFL teaching approach. When they become teachers, they do not forge new meanings of teaching Chinese out of nothing, rather they create a professional identity that bears relation to meanings of teachers and teaching in wider educational and social contexts, that is, 'Chinese' and/ or 'Danish' context, and beyond. Further, as Deardorff (2004) proposed in the 'Process Model' of intercultural competence, the ability to specify the interrelationship among different cultures is also essential to developing intercultural competence with each stage facilitating the next one. In the case of Frank's teaching method, identifying his teaching method as 'Danish' or 'Chinese' is no longer so important; instead, finding a suitable and applicable way to make a sense of what he did is of great importance. Secondly, identity is fundamentally contingent, not fixed for all time according to where you come from, but fluid, in light of changing circumstances, according to where you are heading for in your professional path. Also, our study pointed to the importance of personal intercultural experience in constructing a professional identity. In an egalitarian society such as Denmark, the starting point is not to impose authority on the students, rather to create an environment where students enjoy themselves in CFL learning. In a professional context, they expect that it is their empathetic ability to understand students' learning difficulty and communicating their 
knowledge deserve students' recognition. In a personal context, even though they come from Denmark, by a certain point they have been operating in a Chinese context for years. Being regarded as 'foreign students' in China suggests that their learner identities lock them into a particular category. Living with the way in which their Danish students regard them and how they actually understand the path of Danish students set on, suggests that multiple identities do them good in that they leave space for the kinds of shifting identities associated with being part of more than one linguistic and cultural grouping.

\section{Recognising the Merits of Non-native CFL Teachers}

Non-native teachers need to recognise their special merits; which native teachers may not have. A shared mother tongue between non-native CFL teachers and their students is a useful pedagogical tool, in terms of teacher-student interaction, which may help make the Chinese language more approachable. They have gained knowledge of 'learning trajectory' in student-teacher interaction. It is vital that non-native CFL teachers understand the difference between 'native speaker identity' and 'professional teacher identity' (Moussu and Llurda 2008). The former was found more desirable for non-native speakers to obtain acceptance by the Chinese-speaking community. Nevertheless, native proficiency does not necessarily transfer to effective Chinese languageteaching practice. Evidence reveals that Agnes and Frank continue to experience improved pedagogical and intercultural knowledge, which enable them to construct teacher identities within home country. Despite the fact that native speakers are often seen as, or presented as a reliable source of linguistic data, non-native teachers may demonstrate an equally successful model of intercultural learning and communication, teaching, or sharing students' foreign language learning skills and attitudes, based on their personal experiences as language learners. The current findings reinforce the dynamic and multiple nature of foreign language teacher's identity (Varghese et al. 2005). More importantly, as Agnes and Frank initially disagree the 'Chinese' way of teaching CFL and avoid using it. They later succeed in combining or finding compromises between Danish and Chinese approaches to teaching Chinese. In other words, they create a new teaching approach different from 'Chinese' and 'Danish' ways. The meaning of this teaching approach is context (Danish setting) as well as discipline (Chinese 
language teaching) sensitive. In the end, we begin to see how a nonnative CFL teacher as an active agent to develop a 'trajectory' appropriate to the settings and cultures. The competence of creating a new teaching way was born out of the lived experience of understanding both classroom cultures embedded in a home and host university (Zhu 2014). This is what we called an intercultural awareness. Thus, for Agnes and Frank, teaching CFL in their home country is a further step on a journey of self-discovery in which they are able to fulfil personal and professional satisfaction, and they had achieved success despite various linguistic, pedagogical, and cultural challenges.

\section{Implications and Future STUdy}

The educational implications of our findings to CFL teacher educators and CFL teacher programme are listed. Our findings suggest it is potentially important for future empirical work in CFL teacher education to explicitly consider the impact of teachers' experiences as a language learners and the experience of intercultural education. In practice, educating non-native CFL teachers should pay more attention to teachers' past learning experience, especially listening to their motives of choosing the subject, recognise their effort in securing their commitment to CFL teaching, and leave space for them to develop their ways of language teaching. As a non-native CFL teacher, born and educated outside China, the first step for CFL teacher programmers is to strengthen intercultural education in the teacher programme in their teaching practicum within home country. Strengthening intercultural education should not only centre on imparting teachers to cultural facts or cultural knowledge. Rather, it should focus on encouraging them to be reflective upon their learning and teaching experience, and to be critical of the content they teach and of context they are situated in. Secondly, sharing a similar learning experience with the local students is a pedagogical plus in language teaching. Yet, lacking pedagogical content training in teaching CFL poses a problem. When we heard from Agnes making comments like, 'we were never taught how to teach [TCFL] to Danes [while I was a student]', education in the pedagogical content knowledge of TCFL is needed while they were the language learners at home and at host universities. Lacking a solid knowledge backup, it is hard for non-native teachers to develop professional identity. 
Inevitably, there are certain limitations that have been imposed on the current study that should be acknowledged at this point. Given the limited number of teacher participants, readers should interpret the research results with caution. The study presented has only dealt with two non-native CFL teachers within a limited period of time. For this reason, future studies on non-native teachers may look at the development of their profession by following them over a number of years. Secondly, we have to acknowledge the inherent limitation of the narrative approach as a research inquiry adopted in this study. Although we strive to be distanced and be objective, the influence of our own experience and interpretation can hardly be ignored. Nevertheless, it is hoped that our study will shed light on the significance of CFL teachers' professional identity study and call for more research, so as to allow more solid conclusion to be drawn.

\section{REFERENCES}

Beijaard, D., Meijer, P., \& Verloop, N. (2004). Reconsidering research on teachers' professional identity. Teaching and Teacher Education, 20, 107-128.

Britzman, D. (2003). Practice makes practice. A critical study of learning to teach. Albany, NY: State University of New York Press.

Clarke, M. (2008). Language teacher identities: Co-construction discourse and community. Clevedon, UK: Multilingual Matters.

Connelly, F. M., \& Clandinin, D. J. (1990). Stories of experience and narrative inquiry. Educational Researcher, 19(5), 2-14.

Deardorff, D. K. (2004). The identification and assessment of intercultural competence as a student outcome of internationalization. Raleigh: North Carolina State University Press.

Dörnyei, Z., \& Ushioda, E. (Eds.). (2009). Motivation, language identities and the L2 self. Bristol: Multilingual Matters.

Gibbs, G. (2007). Analyzing qualitative data. London: Sage.

Gu, Q., \& Day, C. (2013). Challenges to teacher resilience: School context matters. International Journal of Leadership in Education: Theory and Practice, 16(3), 301-326.

Hammerness, K., Darling-Hammond, L., \& Bransford, J. (2005). How teachers learn and develop. In L. Darling-Hammond \& J. Bransford (Eds.), Preparing teachers for a changing world: What teachers should learn and be able to do (pp. 358-389). San Francisco, CA: Jossey-Bass.

Moloney, A. R. (2013). Providing a bridge to intercultural pedagogy for native speaker teachers of Chinese in Australia. Language, Culture and Curriculum, 26(3), 213-228. 
Moussu, G., \& Llurda, E. (2008). Non-native English-speaking English language teachers: history and research. Language Teaching, 41(3), 315-348.

Orton, J. (2011). Educating Chinese language teachers - some fundamentals. In L. Tsung \& K. Cruickshank (Eds.), Teaching and learning Chinese in global contexts - CFL worldwide (pp. 151-165). New York: Continuum International Publishing Group.

Starr, D. (2009). Chinese language education in Europe: The Confucius Institutes. European Journal of Education, 44(1), 65-82.

Strauss, A., \& Corbin, J. (1990). Basics of qualitative research. London: Sage.

Trend, J. (2013). Becoming a teacher educator: the multiple boundary-crossing experiences of beginning teacher educators. Journal of Teacher Education. Retrieved from online. http://jte.sagepub.com/content/early/2013/01/ 28/0022487112471998.

Tsui, A. (2007). Complexities of identity formation: A narrative inquiry of an EFL teacher. TESOL Quarterly, 41(4), 657-680.

Varghese, M., Morgan, B., Johnston, B., \& Johnson, K. (2005). Theorizing language teacher identity: Three perspectives and beyond. Journal of Language, Identity and Education, 4(1), 21-44.

Wang, D., \& Kirkpatrick, A. (2012). Code choice in the Chinese as a foreign language classroom. Multilingual Education, 2(3). Retrieved from online. http://www.multilingual-education.com/content/2/1/3.

Wang, D., Moloney, R., \& Li, Z. (2013). Towards internationalizing the curriculum: A case study of Chinese language teacher education programs in China and Australia. Australian Journal of Teacher Education, 38(9), 116-135.

Wang, L., \& Jensen, A. A. (2013). Cultural influences on Chinese language teachers' perceptions and beliefs in a Danish context. In M. Kirkebæk, X. Du, \& A. Jensen (Eds.), Teaching and learning culture (pp. 95-112). Rotterdam: Sense Publishers.

Wenger, E. (1998). Communities of Practice. Cambridge: Cambridge University Press. Zhang, C., \& Jensen, A. A. (2013). Professional identity Construction of nonnative Chinese language teachers. In M. Kirkebæk, X. Du, \& A. Jensen (Eds.), Teaching and learning culture (pp. 113-127). Rotterdam: Sense Publishers.

Zhu, H. (2014). Exploring intercultural communication: Language in action. London: Routledge.

Zhang Chun is Principal Teaching Associate Professor of China Studies in Aarhus University, Denmark. She specialised in teaching Chinese as a foreign language and Chinese teacher education. Her publications include more than 20 articles and book chapters, including latest articles Speech Rhythm of the Danish-Chinese Interlanguage (co-author, conference proceedings, October, 2015) and Discursive Construction of Chinese Language Teacher Identity (author, Palgrave 
Macmillan, October, 2015). She also initiated a project entitled 'NordNet TCFL 2016', a network aiming to improve the quality of TCFL (teaching Chinese as a foreign language) within Nordic universities.

Wang Danping is Lecturer in Asian Studies at the University of Auckland, New Zealand. She received her BA in English and MA in Chinese Linguistics from Renmin University of China, and her doctorate at the Education University of Hong Kong. She has taught Chinese as a second and foreign language at different levels in schools and universities in Beijing and Hong Kong for over 10 years. In 2014, she was granted the Teaching Excellence Award for her innovative teaching approach in Hong Kong. She has been the recipient for two times of the SinoBritish Fellowship to visit the University of Cambridge and the University of Oxford in the UK. She has published extensively on research topics related to Chinese language teaching and learning, teacher development, language policy, bilingual education and bilingualism. Her research project on Chinese as a second language education was funded by the Hong Kong Research Grants Council in 2016. 